\title{
Practical Answers: A platform for knowledge sharing
}

\section{ROBERT CARTRIDGE, NEIL NOBLE and ZBIGNIEW MIKOLAJUK}

The Technical Enquiry Service has provided technical information to development practitioners for 40

years
Access to knowledge and knowledge sharing are critical factors in the success of development projects, but very often people who need knowledge either don't know that knowledge resources exist or cannot access or understand them. Over the years a wealth of knowledge and learning has been developed and collected by Practical Action. These knowledge materials can be accessed through its services known as Practical Answers. Information is provided free of charge to those working to reduce poverty in developing countries such as development practitioners, non-governmental organizations, community groups and small-scale entrepreneurs. This knowledgesharing initiative attempts to stimulate a positive impact on the livelihoods of its target audiences in the South - farmers, smallholders, marginalized social groups. It uses multiple information sources and communication channels, contextualizes technical information, acts as a broker and quality assuror for information from diverse sources, and seeks feedback from users about the appropriateness and impact of the information. The water and sanitation sector is a significant knowledge and information services area for Practical Answers.

Keywords: knowledge sharing, impact assessment.

Poor PeOPle With LITTLE or no basic education have also very limited opportunity and capacity to benefit from a wealth of information materials available in electronic media and traditional libraries. The Practical Answers project tries to address this problem through the Technical Enquiry Service (TES) that has developed over 40 years. It provides technical information to development practitioners across Asia, Africa and Latin America. From fruit drying to water pumps and rainwater harvesting to solar energy, the information specialists spread across eight offices answer 3,500 individual enquiries a year. The information materials (technical briefs, guides and manuals) are also available online (www.practicalanswers.org). The website has around three-quarters of a million hits (webpage requests) a year. In September 2006 consultants working for DFID said of Practical Action's Technical Enquiries Service that 'It is hard to imagine many other development projects that could provide such good value for money' (Rowley et al., 2006). 
The impact of one particular service on poverty is almost impossible to measure but individual case studies and anecdotal evidence suggest that technical briefs have been used, for example, to introduce new technologies and solutions in producing vegetable oil, improving water supply and sanitation, and energy supply.

This article looks at the knowledge-sharing philosophy and practice behind Practical Answers and some of the challenges that face it as it moves into its fifth decade.

\section{Knowledge sharing}

Sharing information about appropriate technologies which could leverage people from poverty was a founding principle of the Intermediate Technology Development Group (now Practical Action). But what started as a reaction to the neo-colonial 'we have all the answers to your poverty' approach has now developed into a much more sophisticated multi-dimensional dialogue between development practitioners and people living in poverty, which seeks genuinely to understand how, and under what circumstances, the application of different technologies can effectively contribute to the reduction of poverty.

But there is much more to learn. As well as service delivery, Practical Answers is currently being run as an action research project which is attempting to:

- assess the demand for the application of technologies and research results in diverse environments (demand mapping);

- strengthen information linkages among all agents of innovation processes and improve communications between knowledge suppliers and users;

- create and stimulate the market for knowledge products (local and global);

We need to

- demonstrate and develop effective processes and facilities for accessing knowledge products by diverse groups of users;

understand the barriers that poor people face in obtaining useful information

- understand how promotion and widespread use of knowledge products can contribute to poverty reduction and economic growth;

- understand the barriers that poor people face in obtaining useful information.

The current role of Practical Answers in a knowledge-sharing system is illustrated in Figure 1. 


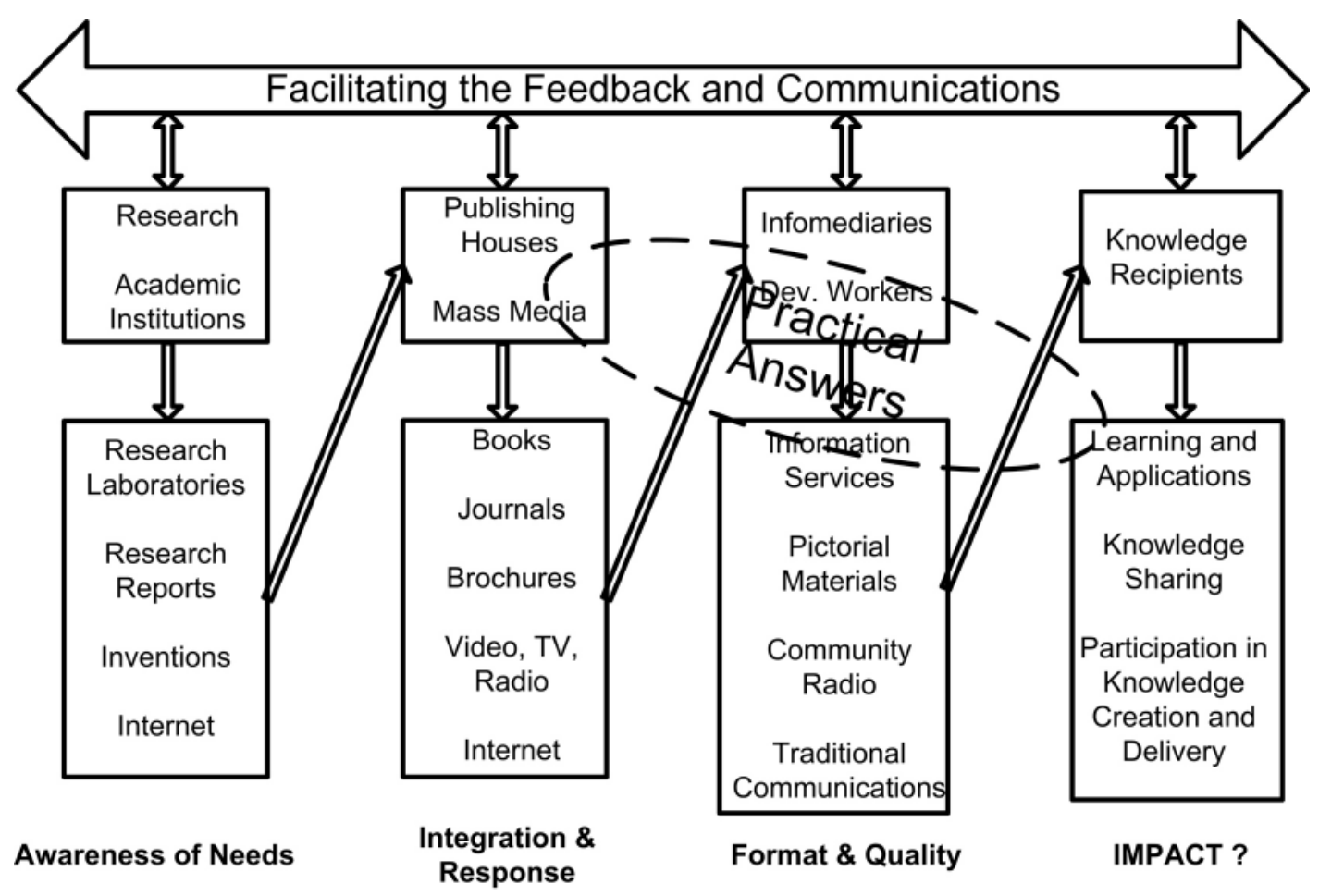

Figure 1. The role of Practical Answers in linking knowledge suppliers and users

Information in local languages is limited, which marginalizes people without formal education
Much of the technical information that is available is not aimed towards the needs of poor people in developing countries but is generated by and aimed at people in Western economies and their research objectives. Scientific and technical publications as well as other materials published in paper format or on the internet usually can only be understood and used by educated people who have access to communication media. Information in local languages is limited, further marginalizing people without formal education and no broadband access to the internet. For example, a simple search on Google for 'water and sanitation' gives 1,040,000 hits. Almost all materials, from the World Bank's reports to technical guides and brochures, are in English. Hundreds of websites maintained by institutions dedicated to research on water and sanitation face the same problem, how to make the wealth of knowledge available to those who need it most.

Practical Answers is a component in the process of transferring knowledge from experienced individuals and contained in publications and research reports to people who need to solve their practical problems in such areas as water supply, food production, agricultural production, small business development, transport and energy. 
Extension workers or development workers are often needed to deliver information effectively
Critical issues are the transformation of scientific and technical materials into a format more suitable for targeted users and integration with indigenous knowledge. In many cases information intermediaries (or as we call them infomediaries) such as extension workers or development project staff are needed to provide effective delivery of knowledge materials.

\section{Linking knowledge resources with their users}

So what has the Practical Answers experience taught us about how we can get existing knowledge and information to the people who need it and can use it? This is a challenge around the world, and nowhere more so than in developing countries, where the needs are so great and where communication pathways are mostly underdeveloped, or even nonexistent.

Over the years a wealth of data, information and knowledge has been developed, collected, produced and archived on a huge range of topics, but very often the people who need it either do not know that it exists or cannot access it. The resources include such diverse components as government statistics on people, land use, production, and so on; point and average meteorological data; published and unpublished printed material such as project reports and publications on successful and unsuccessful development initiatives and handbooks on appropriate methodologies and technologies; audio-visual materials; maps; and lists of resource people. Most of this material is likely to be useful to people other than those who collected it, but it is rarely used as there is no easy way to discover what is available.

To address the issue of knowledge delivery we need to consider multiple routes of access and modes of delivery of knowledge products from online to regular mail and traditional media. Multilingual interfaces ought to be developed to ensure that the knowledge-sharing system can be used by all, from farmers to politicians and scientists. Figure 2 shows an overall operational model of Practical Answers.

The goal of Practical Answers is to contribute to poverty alleviation through improved, sustainable information services that promote the application of appropriate, effective technologies. The core activities of Practical Answers are the Technical Enquiry Service (TES), the Technical Information Online (TIO), Resource Centres (RC), and dissemination of knowledge materials about technologies for farmers and smallholders through mass media.

In this paper we concentrate on operations and results of the Technical Enquiry Service. The aim of TES is to use the accumulated assets of staff knowledge, publications, technical briefs, staff contacts and networks to create value in terms of support for problem solving in response to actual demand for information. Direct contact with 


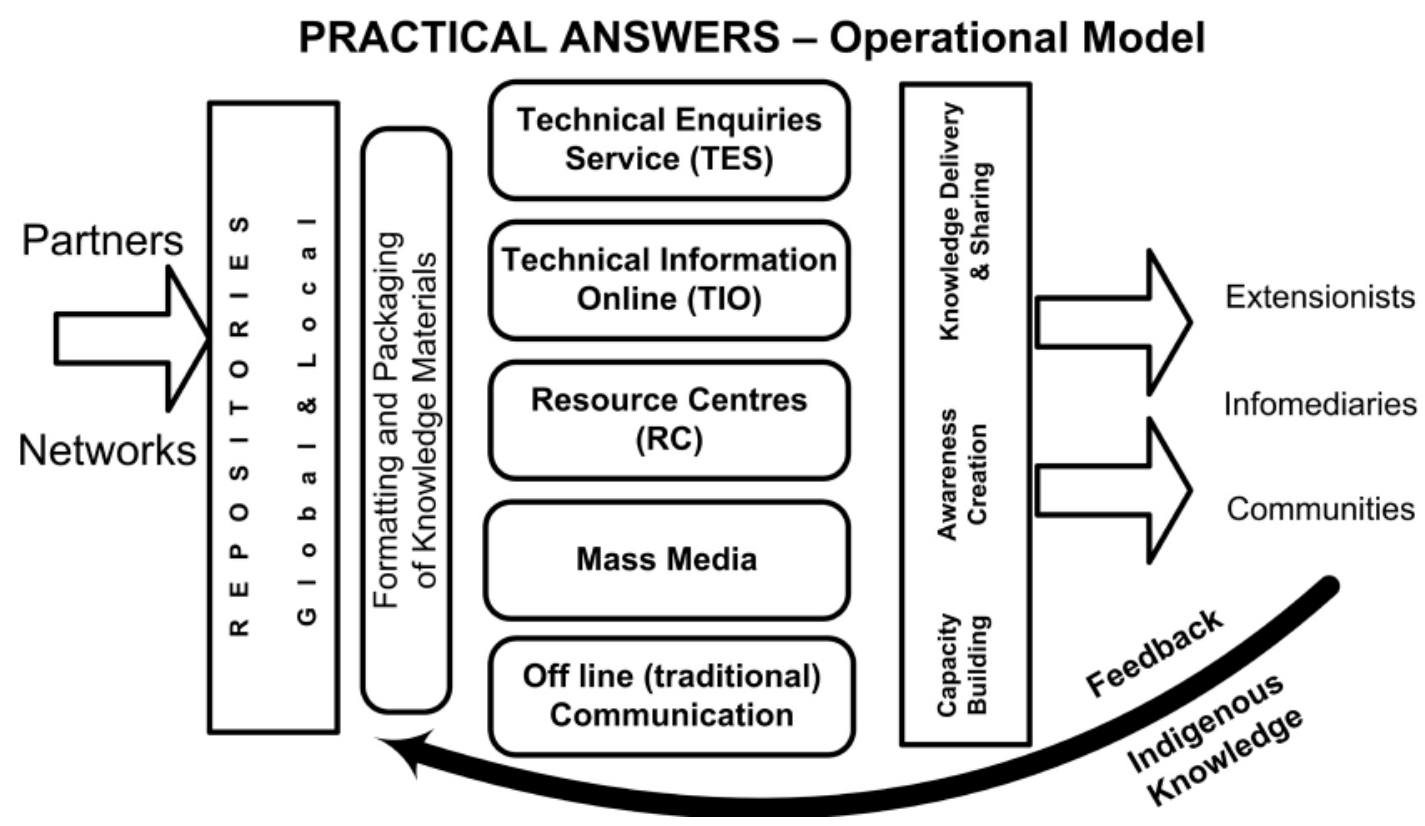

Figure 2. Practical Answers' operational model

From the perspective of knowledge management the Technical Enquiry Service is a primary process at Practical Action people seeking knowledge is an effective way of knowledge sharing and communicating with people who may not have sufficient skills to use information materials made available online. From the perspective of knowledge management TES is a primary process at Practical Action. 'Primary processes are those that are judged essential to an organization's performance. Without these primary processes the organization would not "be in business", it would not have good reasons to exist' (McCann, 2006).

Table 1. Number of enquiries to the Technical Enquiry Service (August-October 2007)

\begin{tabular}{lrlr}
\hline Country office & No. & Enquirer category & No. \\
\hline Bangladesh & 138 & Government & 73 \\
Kenya & 97 & Commercial & 69 \\
Nepal & 28 & Community-based organizations & 8 \\
Peru & 150 & National NGO & 141 \\
Sri Lanka & 85 & International NGO & 76 \\
Sudan & 123 & Individual & 339 \\
UK & 149 & Academic & 51 \\
Zimbabwe & 50 & Student & 1 \\
Total & 820 & Practical Action office & 10 \\
& & Other & 52 \\
& & Total & 820 \\
\hline
\end{tabular}


The enquiries are made mainly by 'infomediaries' - people who work with communities in developing countries and need information

Impact evaluation helps us understand how to improve information materials and their delivery
Table 1 shows some statistical data about TES activities in a recent quarter. The enquiries are made mainly by infomediaries - people who work with communities in developing countries and need information materials to solve specific problems arising in their projects. Our aim is to develop information materials that will be made available in languages and formats appropriate for the ultimate beneficiaries of information, such as farmers, women self-help groups, and smallholders in developing countries.

Practical Answers' activities aim at improving the delivery of knowledge materials, knowledge networking and development communication, and learning about the impact of information service on development. Consequently, Practical Answers' international team seeks a better understanding of needs for technical information in development and the impact of knowledge sharing.

Impact evaluation means the systematic identification of effects, positive or negative, intended or not, on beneficiaries of Practical Answers. Impact evaluation helps us understand how to improve information materials and their delivery. Impact can be conceptualized as the difference between what happened with the project or programme and the situation if the intervention had not been made, i.e. if the information about suitable technologies/solutions had not been delivered and used. The development of a framework for system operations, guaranteeing intellectual property rights, financial sustainability, bilateral and multilateral arrangements, and national and regional agreements will be one of the major tasks of the project.

Table 2 shows the thematic groups of technical briefs that are in the highest demand.

Table 2. Enquiries by theme

\begin{tabular}{lr}
\hline Theme & No. \\
\hline Energy: technology use & 115 \\
Agroprocessing: food & 91 \\
Agroprocessing: crops & 60 \\
Development practices & 60 \\
Construction & 50 \\
Agricultural production & 46 \\
Water and sanitation & 40 \\
Agriculture general & 34 \\
Energy: stoves & 33 \\
Manufacturing and processes & 31 \\
Technology in development & 30 \\
Forestry & 29 \\
Energy sector & 28 \\
\hline
\end{tabular}




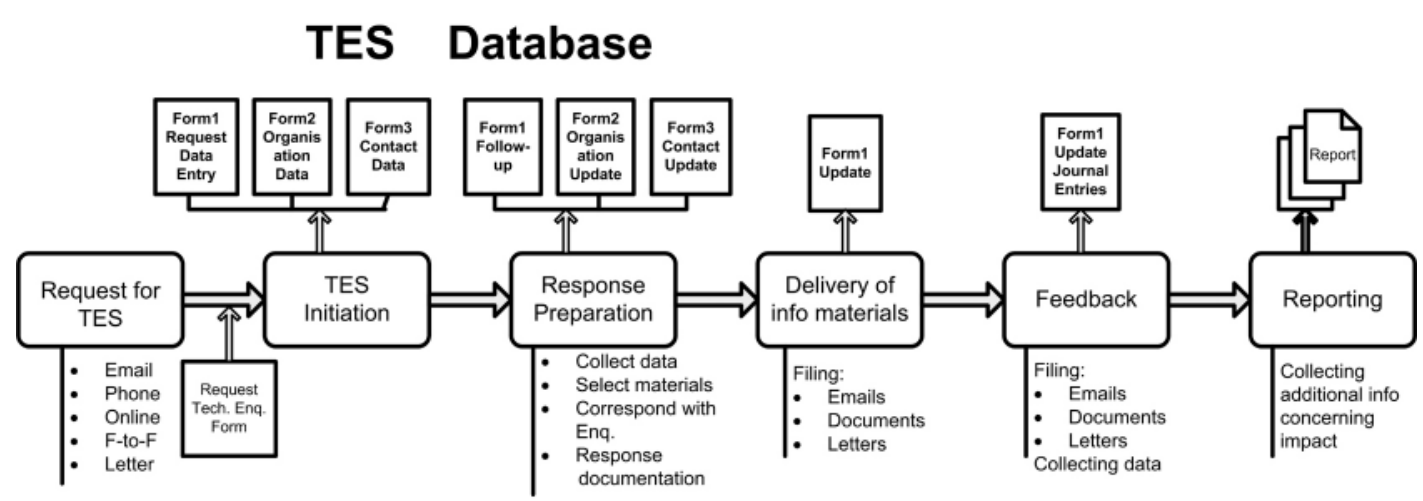

\section{TES Document Repository/Library}

Figure 3. The Technical Enquiry Service process

Gathering evidence of impact should be carried out as part of the TES routine

\section{Technical Enquiry Service process}

The Technical Enquiry Service is a demand-led service beginning when an enquiry is made by filling in the Technical Enquiry Form on the Practical Answers website (see e-mail message in Box 1) or by contacting one of the Practical Action offices by phone, by e-mail, in person, or regular mail (letter). Data on each enquiry is collected within a specially developed database which assists in monitoring, reporting and assessment.

The TES officer or project/extension worker tries to obtain from the enquirer the data needed to initiate the process and as much information about the enquiry and circumstances in which the information is going to be used. The data from the Technical Enquiry Form or a note made by the TES officer is then entered into the database. The follow-up correspondence and activities are recorded in the enquiry monitoring system.

The collection of data and gathering of evidence for impact assessment should be carried out during the entire process (life cycle) of TES, i.e. receiving and recording of enquiry, the preparation of technical information, responding to enquiry, and obtaining feedback. The diagram in Figure 3 shows the process and types of data generated by TES. TES database applications provide data entry forms and report generation tools.

The Practical Answers project and its Technical Enquiry Service have been financed in recent years by grants from DFID and allocations from Practical Action's budget. The main costs of TES include: 
Country offices now provide information

materials in local languages

In Bangladesh

TES services are provided by over

1,000 extension

workers associated

with Practical

Answers on a

voluntary basis
- human resources (TES officers in the UK and seven country offices);

- production and update of technical briefs and other information materials;

- website development and maintenance;

- communications and materials delivery.

Initially TES activities were concentrated in the UK office with a full-time officer supported by short-term contractors. In recent years, Practical Action's country offices expanded their services and included delivery of information materials in local languages (see Table 3). The TES tasks are carried out by Practical Answers project staff. The Zimbabwe office is currently partnering with 12 local NGOs and CBOs for the delivery of the service. They also work in close collaboration with government ministries and agencies, academic institutions and scientific research institutions such as the Scientific and Industrial Research and Development Centre (SIRDC). All offices benefit from collaboration with volunteers and extension workers who collect enquiries about technologies and use Practical Action's materials to provide the required information. For example, in Bangladesh TES services are provided by over 1,000 extension workers associated with Practical Answers on a voluntary basis. We may add that globally over 30 employees are providing TES services on a full- or part-time basis in collaboration with hundreds of volunteers and associated extension workers.

The Technical Enquiry Service is a major part of the information services provided by Practical Answers (formerly by the Programme Management Unit in Policy Division). Total expenses for the period 2002-2006 have been estimated at $£ 720,000$. Since 1968, information services and technical support have also been embedded in many

Table 3. Numbers of staff working on technical enquiries

\begin{tabular}{|c|c|c|c|c|}
\hline Country office & & Full-time & Part-time & Additional outreach \\
\hline Peru & & 1 & 4 & \\
\hline Kenya & & 1 & 1 & \\
\hline \multirow[t]{3}{*}{ Sudan } & Country office & 1 & & \\
\hline & Kassala office & 1 & & 2 volunteers plus 10 extension workers \\
\hline & Darfur & & & 3 volunteers \\
\hline Zimbabwe & & 1 & 1 & $\begin{array}{l}12 \text { local NGOs and CBOs; government } \\
\text { ministries; research institutions }\end{array}$ \\
\hline Sri Lanka & & & 4 & \\
\hline Nepal & & 1 & 2 & \\
\hline Bangladesh & & 3 & 20 & 1000 volunteers \\
\hline
\end{tabular}




\section{Box 1. A typical enquiry}

Back in April 2003, Mr Shabab Wahid, an engineer working in the northern area of Pakistan, contacted Practical Action by email: 'I am an engineer working in public sector development. We are trying to build a tyson turbine for water lifting. Could you guide us? We would like you to inform us of the website or library from where such information could be obtained.'

In December $2005 \mathrm{Mr}$ Shabab Wahid was designing and developing hydropower schemes at a mini and micro level and wrote to Practical Action with a problem. He had been looking at a design of a low-cost, low-head, micro hydro axial turbine that had been developed by the Practical Action office in Peru.

Soluciones Pràcticas (Practical Answers' Latin America office, based in Lima, Peru) developed a low-head axial turbine that was designed for local manufacture at low cost. The design proved to be successful in Peru and it was made available to others on the internet where it was intended that people could take the design and adapt it to their own ends.

The difficulty was that the document Mr Wahid found on the website that explained how to make the turbine was in Spanish in a document called Guia de Fabrication and, although he had made good progress from the engineering drawings that he had also picked up from the website, there were a few details that were troubling him.

Mr Wahid said 'I have downloaded the drawings, summary and the assembly guide from your website... One file regarding the machining and manufacturing the components of turbines especially the runner blades etc is not available on the website'. And went on to say 'would you let me know the how to fabricate the runner and its vanes. Fabrication of other components is easy. I am stuck on the runner. The drawings of the runner made available by ITDG [as we were called then] are not sufficient for fabrication of runner'.

Through the Technical Information Service Practical Action was able to translate the construction manual, at least in draft form, into English which allowed $\mathrm{Mr}$ Wahid to complete the manufacture and installation of the 37 kilowatt turbine which now provides electricity to 50 households.

Recently Mr Shabab Wahid provided some feedback on the work he has been doing in Pakistan and said, 'The service provided by your group is very beneficial. The information provided by you earlier was extremely helpful and approximately fifty household (400 souls) benefited from the information provided. We want you to continue this service.'

Mr Wahid first contacted the Technical Enquiry Service in 2002 and over the years Mr Wahid has called upon the service on many occasions regarding various aspects of energy delivery. He has investigated the water current turbines developed by Peter German at ITDG some years ago and later continued by a company set up by Peter German called Thropton Energy Service. These turbines can be used to generate electricity or pump water. They are designed to float in the current of a river or stream and require virtually no installation and can be moved whenever required. As they are floating devices they are less susceptible to flooding.

Mr Wahid has also asked about electronic load controllers from Nepal so there is a link between Pakistan and Practical Action Nepal as well as Practical Action in Peru. He is currently looking to improve his casting facilities to make blades for his turbines. 
An enquiries service needs time for funders to see the impact of their investment
A significant number of enquiries on some issue in a certain region may indicate that Technical Briefs are needed projects. The estimation of the total cost of these services over a period of 40 years would be quite laborious.

The Practical Answers team has begun a thorough analysis of TES activities and demand for knowledge. We aim at developing a new model for sustainable operations. We are also considering a commercial option in which small local enterprises (for example telecentres, training institutions, farmers' schools) would provide knowledge brokerage, information delivery and access to online resources. In this model, our role would be the facilitation of networking, support for developing quality materials and promotion of innovations.

\section{Impact assessment}

Practical Answers needs to better understand the impact of information services in changing social environments (diverse groups of knowledge seekers) and recent technological advances, so that it can allocate precious resources most effectively. Information materials must be updated more frequently and better tailored to local needs. One of the biggest challenges facing Practical Answers - like all knowledge sharing networks - is sustainability. Funders work in the short term, while an enquiries service needs some time to build up momentum in order for funders to see the impact of their investment.

The data collected about dissemination of knowledge materials allow for the production of summary and statistical quantitative reports such as the number of interventions per country, region, subject and type of intervention. The reports indicate where further investigation should take place to find indicators of impact of knowledge sharing.

For example, a significant number of enquiries about technologies for water purification in a certain region may indicate that Technical Briefs are needed and would be useful in solving the problem. In this case we may look at the indicator/evidence of usefulness of technical assistance based on delivered information. The impact indicator will be based on statistical data as well as reports from missions to the region, testimonies from the local population and, for example, data from WHO surveys indicating the decrease in number of cases of water-borne diseases.

We must keep in mind that the collection of data and in particular meaningful impact assessment are costly procedures. The investment of financial and human resources must be justified by the improvement of services and therefore greater positive impact. We have to resolve problems of duplicating manual data entry and collection and analysis of qualitative information (documents, e-mails, surveys, stories, etc.). Short messages and opinions from people who received and applied technical information are valuable starting points 
for taking the decision to conduct comprehensive impact assessment. Box 2 gives some examples of opinions expressed in the recent TES survey.

The main objective of impact assessment is the confirmation or refutation of the conclusion that long-term effects produced by knowledge sharing contribute to poverty alleviation and improvement of livelihoods.

Impact on poverty alleviation and improvement of livelihoods can be characterized by the following indicators:

- employment opportunities;

- income opportunities;

- better living conditions;

- access to services.

\section{Box 2. Responses to an impact survey}

Q: What can you tell us about the role that our technical information has played in your project? (68 respondents, 11 skipped the question)

'The Rainwater Harvesting guide was a useful introduction to building ferrocement tanks for rainwater catchment.'

'. . . because we work with people from refugee and immigrant backgrounds, your technical information has helped us raise awareness of the means and ways that they can support people back in their home countries if they learned and later transferred the knowledge acquired to the local people' 'Very useful information - helped to put together a manual on processing of fruit and vegetables for use at household level in Afghanistan.'

'Much was downloaded - put onto CDs and distributed in Southern Africa for rural development, helping the poor... Thank You!!!'

'We use the information of Practical Answers to work with a rural community about access to domestic water and we use examples in Africa and Peru to understand in a better way how we can work with more quality and efficiency in this issue.'

Q: How has our service contributed to its aim of reducing poverty? (66 respondents, 13 skipped the question)

'Through the development of the skills of our staff and partners, we are contributing to a better understanding of vulnerabilities and risks and through appropriate programming we are addressing some of the root causes of poverty.'

'Saving money on experts and giving us a chance to offer a cheap do-ityourself solution to the poorest of the poor.'

'The service saves money on experts' 'The participants collect plastic from the garbage. They are now learning to recycle it. Their incomes will definitely increase.'

'While the systems we have installed have not directly reduced poverty they help to improve the lives of poor remote and rural communities. The system frees time from chores (such as fetching water) or helps to increase working hours (through lighting) and therefore should allow more time for education or livelihood applications.' 
The income indicator needs to be related to baseline information on opportunities existing before the intervention
We need to understand who needs the knowledge, what format they want it in and what knowledge they need
The employment opportunities indicator may be linked to the introduction of new technologies in the community or larger geographical area. For example, if a significant number of new water pumps or micro-hydro power stations had been installed then the employment opportunities indicator would tell how many operators and maintenance workers are needed and in some cases what additional jobs may be created because of better availability of water and electric power.

The income opportunities indicator needs to be related to opportunities existing before the intervention (baseline data), i.e. interventions undertaken as a result of responses to technical enquiries from an organization, project or community. In addition to data about received enquiries we would need the data from an employment authority and stories from people who have benefited and increased their income.

The living conditions indicator is a complex indicator that encompasses many types of data about all aspects of livelihoods. Technical interventions resulting from technical enquiries may contribute, for example, to the improvement of hygiene, better drinking water, transportation, use of energy resources, better housing, etc. To assess the impact of these technical interventions we would need data from development projects and official statistics. It may take quite some time to obtain these data: for example, waiting for census data.

The access to services indicator can be linked to Practical Answers through enquiries concerning communication facilities, and availability of information established as a result of technical enquiries. It would be good to know the status of services availability before interventions or at least the opinions of the local population.

\section{The market for knowledge}

Practical Answers is by no means alone in providing technical information to development practitioners. One of the biggest challenges it currently faces is better understanding the market for technical information at the grassroots level.

On the demand side we need to understand who needs the knowledge, what format they want it in and what knowledge they need. We need to understand the extent of the untapped market - the people who could benefit from the knowledge but do not know of its existence. We began the analysis of demand and impact in our country offices in Sri Lanka (the TES formally in operation here since 1999) and Peru (in operation since 2002) where we can find reliable data and well-established relations with local communities. In Sri Lanka we can investigate the demand in a few chosen local communities (some with internet access and some without). In Peru we will 
investigate a sector-specific project delivering knowledge to the dairy sector in the Cajamarca Region as a response to demand from local communities and the local administration.

On the supply side we are actively maintaining partnerships with other knowledge providers and networks, and explore resources and activities available online. In the water sector these organizations include: WaterAid, WaterPartners International, American Water Works Association (AWWA), Gender and Water Alliance (GWA), Institute of Water and Sanitation Development (IWSD), The International Network on Water, Environment and Health (UNI/INWEH), International Water and Sanitation Centre (IRC), Water, Engineering and Development Centre (WEDC), Water Supply and Sanitation Collaborative Council (WSSCC) and International Water Management Institute (IWMI).

We need to understand the boundaries of our own knowledge and have decent referral networks for areas that we cannot fully cover. And we need to supply information and knowledge to other existing networks. Our mission is to reduce poverty, not to corner the market in knowledge, so we must explicitly develop relationships with other knowledge providers to distribute appropriate knowledge as widely as possible, whilst meeting the quality assurance challenges that this brings.

We now see giving information as including plenty of opportunity for dialogue

Above all else we need to practice what we preach - knowledge is not owned in the developed world so we must find ways through communities of practice and online feedback, for practitioners in the field to feedback their experience, and indigenous knowledge that could be of benefit to others around the world. This is achieved on the website through feedback boxes, but with individual enquiries we now see giving information as being much more of a process in which there is plenty of opportunity for dialogue.

\section{References}

Rowley, J., Cranston, P., Mowles, C. and Wallace, T. (2006) An Evaluation for DFID of the Technical Enquiry Service of Practical Action, Final Report, ITAD, Hove, UK.

McCann, B. (2006) Knowledge and Information Management in the Water and Sanitation Sector: A Hard Nut to Crack, Thematic Overview Paper 14, IRC International Water and Sanitation Centre, Delft, the Netherlands. 